\title{
A competitive mechanism selecting verb-second versus verb-final word order in causative and argumentative clauses of spoken Dutch: A corpus-linguistic study
}

\author{
Gerard Kempen $^{\mathrm{a}, *}$, Karin Harbusch ${ }^{\mathrm{b}}$ \\ ${ }^{a}$ Max Planck Institute for Psycholinguistics, P.O. Box 310, 6500 AH Nijmegen, The Netherlands \\ ${ }^{\mathrm{b}}$ Faculty of Computer Science, University of Koblenz-Landau, Universitätsstraße 1, 56070 Koblenz, Germany
}

\section{A R T I C L E I N F O}

\section{Article history:}

Received 16 July 2017

Received in revised form 13 January 2018

Accepted 4 May 2018

Available online 19 May 2018

\section{Keywords:}

Causative sentences

Argumentative sentences

Verb-second

Verb-final

Dutch language

Corpus linguistics

\begin{abstract}
A B S T R A C T
In Dutch and German, the canonical order of subject, object(s) and finite verb is 'verbsecond' (V2) in main but 'verb-final' (VF) in subordinate clauses. This occasionally leads to the production of noncanonical word orders. Familiar examples are causative and argumentative clauses introduced by a subordinating conjunction (Du. omdat, Ger. weil 'because'): the omdat/weil-V2 phenomenon. Such clauses may also be introduced by coordinating conjunctions (Du. want, Ger. denn), which license V2 exclusively. However, want/denn-VF structures are unknown. We present the results of a corpus study on the incidence of omdat-V2 in spoken Dutch, and compare them to published data on weil-V2 in spoken German. Basic findings: omdat-V2 is much less frequent than weil-V2 (ratio almost $1: 8$ ); and the frequency relations between coordinating and subordinating conjunctions are opposite (want $>>$ omdat; denn $<<$ weil). We propose that conjunction selection and V2/VF selection proceed partly independently, and sometimes miscommunicate-e.g. yielding omdat/weil paired with V2. Want/denn-VF pairs do not occur because want/denn clauses are planned as autonomous sentences, which take V2 by default. We sketch a simple feedforward neural network with two layers of nodes (representing conjunctions and word orders, respectively) that can simulate the observed data pattern through inhibition-based competition of the alternative choices within the node layers.
\end{abstract}

(c) 2018 Elsevier Ltd. All rights reserved.

\section{Introduction}

In modern Dutch, word order of subject, object(s) and finite verb in main clauses differs from that in subordinate clauses: verb-second (V2) and verb-final (VF), respectively. Explanatory clauses (expressing causative or argumentative relations) may manifest either order: verb-final is mandatory after the subordinating conjunctions omdat and doordat (both translatable as because), verb-second after the coordinating conjunction want ('since', 'for'). This difference mirrors the situation in German, with weil 'because, since, as' licensing verb-final, and denn 'for' licensing verb-second word order. In this paper, we focus on a phenomenon readily observable in spoken Dutch and German: verb-second word order in subordinate clauses introduced by omdat/weil. We will refer to the resulting structure as omdat-V2 and weil-V2. The clause in (1), from a recent paper on omdatV2 by Degand (2016), is a case in point, with the finite verb heb in V2 position:

\footnotetext{
* Corresponding author.

E-mail addresses: gerard.kempen@mpi.nl (G. Kempen), harbusch@uni-koblenz.de (K. Harbusch).
} 
(1) ...omdat ik heb tot half één tentamen

... because I have till half one exam

'... because I have an exam till 12:30'

Following Reis (2013), we use the terms explanatory clause or explanans to refer to a clause whose proposition denotes an event or state of affairs causing or explaining another event or state-the effect. The clause describing the effect will be called explanandum. In line with the literature, we distinguish two types of explanantia (explanatory clauses, often called causative and argumentative, respectively). For convenience (presumably without loss of generality of the theoretical account developed below), we assume that explanandum clauses have the form of main (matrix, root) clauses, hence featuring verb-second position of the finite head verbs.

In the present paper, we describe the omdat-V2 phenomenon in more detail, comparing and contrasting it with weil-V2. The empirical material consists of frequency counts of various types of explanatory sentences extracted from the Corpus of Spoken Dutch (Corpus Gesproken Nederlands, CGN2.0; Hoekstra et al., 2001; van Eerten, 2007). We propose a theoretical account based on the sentence production processes underlying omdat-VF and omdat-V2 structures. This account extends the weil-V2 theory published recently by Kempen and Harbusch (2016). The key notion is inhibition-based competition between (1) subordinating and coordinating causative conjunctions, and (2) between verb-second and verb-final word order in the explanans clauses. These competitions are assumed to partly proceed independently and to sometimes miscommunicate.

We begin by summarizing the main properties of omdat/weil-V2 structures put forward in the literature (for recent surveys, see Persoon et al., 2010; Antomo and Steinbach, 2010; Reis, 2013; Abraham, 2016; Kempen and Harbusch, 2016). We take these to be uncontroversial.

1. Omdat/weil explanans clauses with noncanonical V2 mainly occur in spontaneously (extemporaneously) produced spoken utterances, and to a lesser extent in nonstandard written language (Schäfer and Sayatz, 2017). They are virtually absent in formal/edited written text.

2. They do not occur in subordinate explanans clauses that precede the explanandum (hence, omdat/weil-V2 clauses 'trail' behind their explanandum clause).

3. Explanans clauses introduced by want/denn always follow their explanandum (and are traditionally analyzed as the posterior member of a clausal coordination).

4. Omdat/weil-V2 explanans clauses do not occur as isolated explanantia, e.g., in elliptical answers to waarom 'why' questions.

5. There is no mirror image phenomenon consisting of want/denn clauses with VF order.

In the next section, we describe the design and the main results of the corpus study into the incidence of VF and V2 orders in causative/argumentative sentences of spoken Dutch. Our account of these data and of the similarities and differences between the Dutch and German data patterns is developed in Section 3. In Section 4, we outline how the theoretical account can be implemented in the form of a simple neural net, and how it deals with the (near-)absence of V2 after some lowfrequent subordinating explanatory conjunctions in both target languages. Section 5 summarizes the theoretical account put forward in the two preceding sections. In final Section 6, we briefly discuss relations with extant linguistic theories about omdat/weil-V2.

\section{The corpus study: design and results}

The CGN2.0 treebank contains about 130,000 spoken sentences (dialogue turns) from varied content domains (news, telephone conversations, lectures, etc.). Not all of them were produced spontaneously; we discarded about 3800 sentences with read speech. The sentences had been annotated syntactically with relatively theory-neutral dependency graphs. Using TIGERsearch (König and Lezius, 2003) and JAVA programs written by ourselves, we extracted all sentences that contain one or more tokens of the conjunctions omdat, want, or doordat, with the explanandum preceding the conjunction. This yielded a set of 4220 explanandum-cum-explanante sentences, that is, sentences that include a trailing explanans clause with enough lexical material to determine verb placement unambiguously as either VF or V2. ${ }^{1}$ The explanatory conjunctions we extracted were want, omdat, and doordat. ${ }^{2}$ The resulting data are shown in Table 1.

\footnotetext{
${ }^{1}$ In both target languages, the amount of explanandum-cum-explanante sentences fluctuates around $3 \%$ of the sentences annotated in the form of a dependency graph: 3.3 in the Dutch, 2.6 in the German corpus.

${ }^{2}$ We had to relinquish our plan to analyze clauses introduced with daar. This subordinating conjunction occurred only once, followed by an incomplete clause.

In response to a suggestion by one of the reviewers, we also extracted sentences containing the conjunction aangezien 'as, seeing (that), given (that)'. We found 10 exemplars unambiguously classifiable w.r.t. word order. Of these, five were leading, four were trailing clauses, one was an isolated clause. In one leading and one trailing clause, aangezien constituted a conjunction together with the complementizer dat (aangezien dat). See also footnote 11.
} 
Table 1

Distribution of explanans clause types and connectors in the Dutch and German corpora. Only sentences where the explanans clause trails behind the explanandum clause are included. See also Fig. 2.

\begin{tabular}{|c|c|c|c|c|c|}
\hline \multicolumn{3}{|l|}{ Dutch } & \multicolumn{3}{|l|}{ German } \\
\hline Clause type & $\mathrm{N}$ & $\%$ & Clause type & $\mathrm{N}$ & $\%$ \\
\hline want-V2 & 3364 & 79.7 & denn-V2 & 160 & 16.2 \\
\hline omdat-V2 & 52 & 1.2 & weil-V2 & 336 & 34.1 \\
\hline omdat-VF & 773 & 18.3 & weil-VF & 385 & 39.1 \\
\hline doordat-VF & 31 & 0.8 & $d a-\mathrm{VF}$ & 104 & 10.6 \\
\hline Total & 4220 & 100 & Total & 985 & 100 \\
\hline
\end{tabular}

The Table indicates that the relative frequency of omdat-V2 is considerably smaller than that of its German pendant: 1.2 vs. 34.1 percent of all explanatory clauses (and 6.2\% of all omdat clauses). Also remarkable is the much larger share of want explanans clauses in Dutch compared to that of denn clauses in German (already observed in the same corpus by Spooren et al. (2010)).

In many other respects, the speakers of two languages behaved similarly. When embarking on the explanans clause (i.e., around the connector), they produced more disfluencies (filled or unfilled pauses, hesitations, false starts, etc.) when the ensuing word order turned out to be V2 rather than VF. This contrast occurred after coordinating as well as after subordinating connectors. (For discussion of similar observations in Dutch, see Persoon et al. (2010) and Degand (2016); for German, see Kempen and Harbusch (2016) and the literature cited there.)

Another striking similarity is revealed by an analysis of the incidence and the position of subject NPs consisting only of a personal pronoun in explanans clauses ( $i k$ 'I', jij/je 'you', hij 'he', het 'it', wij/we 'we', etc.). In subordinate clauses (VF), these pronouns have restricted placement options, usually occurring immediately after the conjunction-we refer to this position as the Wackernagel position. In main clauses (V2), including main clauses introduced with want, personalpronoun subjects have two placement options: before the finite verb (that is, immediately after want in an explanans clause), or after the finite verb (only the former option is a Wackernagel position in our sense). The position after the verb is selected when, for information-structural or other reasons, some non-subject constituent has occupied the preverbal position, thus leading to subject-verb inversion. We surmise that competition between subject and non-subject constituents for the Wackernagel position in omdat clauses is one of the conditions leading to disfluencies. The probability for the subject to emerge as winner of such competitions is enhanced if the subject referent is easily accessible (speaker, addressee, topic), and can be encoded grammatically in terms of a short and high-frequent referring expression ( $i k$, je, het). As this hypothesis was supported for German (Kempen and Harbusch, 2016), we also checked it for CGN2.0. To this purpose, we classified the explanans subject NPs into those realized as a personal pronoun (Pers-Pro+) versus those realized in the form of any other construction (Pers-Pro-); and we divided the former class into pronouns at the Wackernagel position (immediately after omdat or want: Pers-Pro $+\mathrm{W}+$ ) or at a later position in the clause (PersPro+ $+\mathrm{W}-$ ). The relative frequencies of the three classes are depicted in Fig. 1, combined with the corresponding German data. The charts show that the overall Dutch and German frequency patterns are similar and that, in both languages, the noncanonical V2 patterns (omdat/weil-V2) resemble the canonical V2 patterns (want/denn-V2) more closely than the canonical omdat/ weil-VF patterns. ${ }^{3}$

\footnotetext{
his example (50) (our glosses):

(a) weil's - nicht anders geht (VF) as'it - not otherwise goes

(b) *weil's - geht nicht anders 'as'it doesn't work otherwise' (cliticized) to weil. Here are three of them:

(c) wei's kommt ein Flug ab achtzehn Uhr fümun'dreißig) as'it comes a flight leaving eighteen o'clock thirty five 'as there comes a flight leaving 18:35' (g425acn1_014_AMA_390010)

(d) wei'ch hab' um zwei Kolloquium as'I have at two colloquium 'as I have a colloquium at two o'clock' (n126kxx0_005_WH1_041050)

(e) wei's geht schneller un' bequemer as'it goes faster and easier 'as it goes faster and easier' (g408acn2_021_ALQ_480010)

(The codes following the examples denote Verbmobil dialogue turns.)
}

3 This finding dovetails with Auer's (1997) observation that, in oral German, pronouns can attach to-in our terminology-weil-VF but not to weil-V2. See

However, in the Verbmobil corpus we also found five counterexamples: weil+pronoun utterances with V2 order although the pronoun is attached 
Personal pronoun subjects in V2 and VF clauses
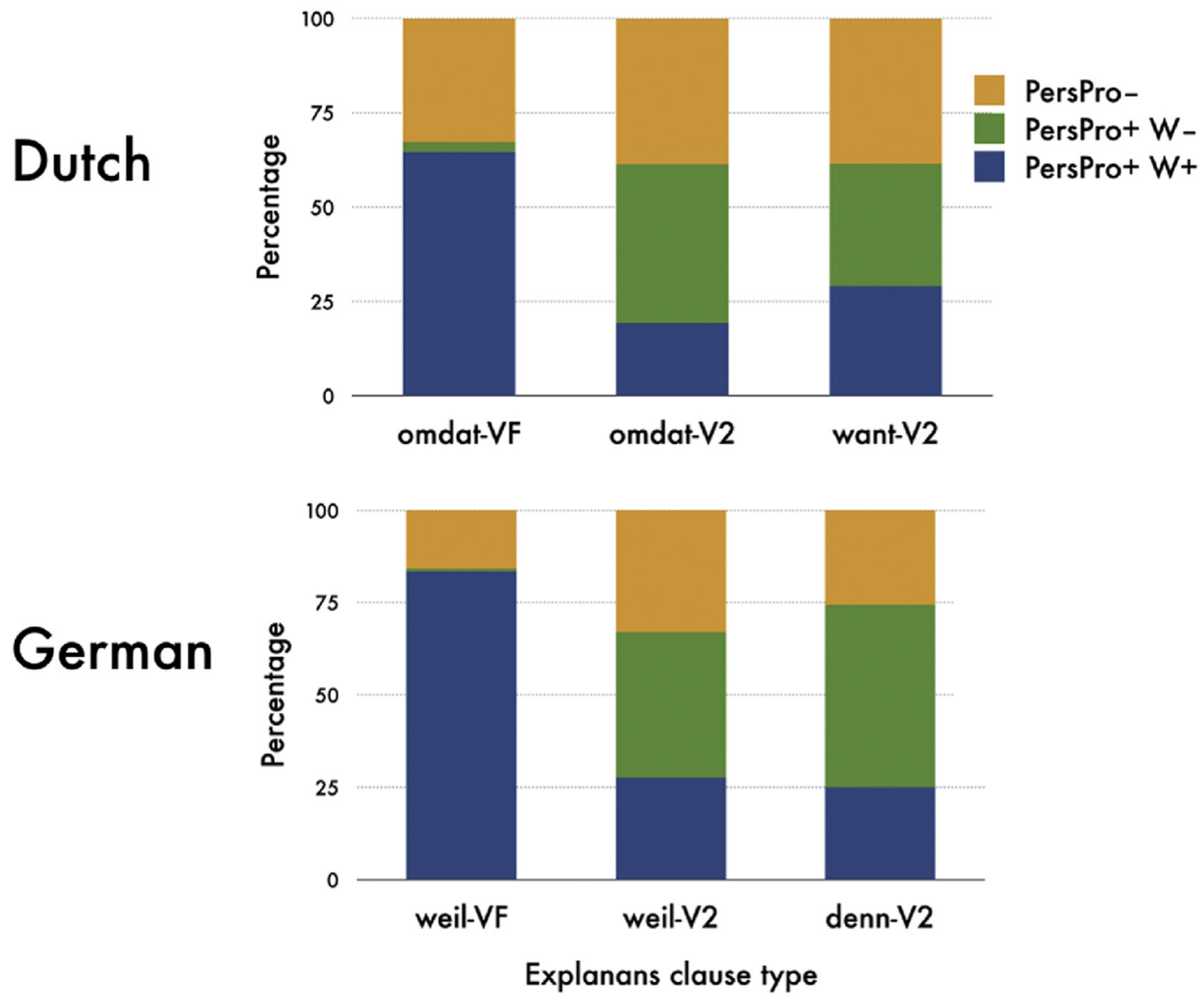

Fig. 1. Distribution of three types of subject NPs in Dutch and German explanans clauses.

In the next section, we summarize the weil-V2 theory developed in Kempen and Harbusch (2016) and apply it to the new Dutch data.

\section{A production-based account of omdat-V2}

Extant linguistic accounts of the omdat/weil-V2 phenomenon tend to focus on the interpretation of explanatory clauses by the conversation partner. Our focus is the production of such clauses.

\subsection{The extemporaneous production of explanatory clauses}

The first step in the production of an explanandum-cum-explanante sentence consists of conceptualizing a communicative intention. Content and form of the conceptualized content-the propositions-underlying the two clauses depends, among many other factors, on whether the speaker assumes these propositions are known or new to the interlocutor, that is, whether they are "presupposed" information, already belonging to the interlocutor's knowledge base ("common ground"), or are an assertion yet to be added to the interlocutor's knowledge base. It is commonly assumed that the speaker will realize presupposed propositions prosodically as backgrounded utterances, asserted propositions as foregrounded utterances. Any (declarative) sentence expresses at least one foregrounded proposition. 
Also in line with standard assumptions in the literature, we assume that a proposition consists of a predicate as head and a set of thematic relations (arguments or adjuncts: actor, patient, recipient, locative, temporal, conditional, etc.) as dependents. Any dependent may be a proposition in itself. This holds for causative propositions the speaker adds as an extra thematic relation to those already expressed in the explanandum. If the explanandum conveys a presupposed proposition, the resulting explanandum-cum-explanante sentence conveys one assertion-one proposition with the explanans as newly asserted and foregrounded dependent. Such a sentence is one type of single-assertion construction, and we call its explanans clause a restrictive modifier (cf. Quirk et al., 1985:1075-1077; Haeseryn et al., 1997:1542-53; Haug et al., 2012:140). In another type of single-assertion construction, it is the explanandum that asserts a new proposition whereas the explanans proposition is presupposed, already present in the speaker's and listener's knowledge base. In such a single-assertion construction, the explanans clause is an appositive modifier. ${ }^{4}$

Consider example (2), where the explanans can be interpreted restrictively or appositively. In the restrictive reading, the speaker assumes the dialogue partner already knows that some drivers got a ticket but not why, and adds speeding as reason (rather than, e.g., illegal parking). In the appositive reading, the speaker assumes the speeding event has already been stored in the partner's knowledge base, and adds ticketing as the consequence (perhaps to emphasize that other drivers in the group got away without a fine).

\section{(2) Some drivers were ticketed because they were speeding}

In order to represent, in the knowledge base, the relation between the proposition underlying a single-assertion construction and the propositions underlying explanandum and explanans, we propose to use inheritance. In the restrictive reading, the proposition underlying (2) inherits the explanandum proposition, in the appositive reading, it inherits the explanans. Inheritance relations can be implemented in terms of pointers from the inherited to the inheriting proposition. In the restrictive reading, proposition (2) inherits the explanandum proposition-thus becoming a specialization/particularization of the latter; in the appositive reading, it inherits the explanans proposition.

However, the speaker may also compose explanandum-cum-explanante sentences in which both propositions are conveyed as new assertions, thus generating double-assertion constructions. Such constructions are also appositive. We will treat such a construction on a par with two separate propositions, each expressed in a separate sentence, connected via a discourse marker, that is, a two-place predicate that takes the explanandum and explanans propositions as thematic arguments. In the present context of causative and explanatory relations, we consider discourse markers expressing predicates such as CausedBy, JustifiedBy, EvidencedBy, SupportedBy, which take the explanandum as first, the explanans as second argument, e.g.,

$$
\text { JustifiedBy(Prop } \left.\text { exp’um }_{\text {, Prop }} \text { exp'ns }\right) \text {. }
$$

Table 2 shows the four possible combinations of a fore- vs. backgrounded explanandum with a fore- vs. backgrounded explanans. As any sentence needs at least one asserted proposition, three combinations remain. ${ }^{5}$ We return to single- vs. double-assertion constructions in Section 6.

Like any other cognitive activity, the process of producing explanatory utterances is liable to mistakes and errors. The speaker may experience sentence planning problems, in particular (1) when setting about to produce an explanandum-cumexplanante sentence but mounting insufficient processing capacity or time to bring the project to a good end, or (2) when deciding to add an explanans clause while the explanandum is already underway, and the explanans is not ready to be uttered

\footnotetext{
${ }^{4}$ Various authors have proposed similar distinctions between types of explanans clauses: between clauses that.

- are or are not functioning as a conventional implicature (Scheffler, 2005),

- are or are not at-issue (Antomo, 2012, 2015, 2016; Charvanel, 2017),

- are centrally as opposed to peripherally embedded (Haegeman, 2006, 2012),

- have an event reading (Ereignislesart) as opposed to a premise reading (Prämissenlesart) (Abraham, 2016),

- form constructions as opposed to configurations (e.g. Debaisieux, 2016).
}

\footnotetext{
Discussing these distinctions and their precise relation to our restrictiveness vs. appositiveness contrast exceeds the scope of the present paper, which focuses on the production rather than the interpretation of causative and argumentative clauses.

5 Reis (2013:256) notes that the speaker may intend to assert only the causal relation between the explanandum and explanans propositions, which then are both presupposed. One of her examples (German; accented word capitalized; our translation):

Paul glaubt andie Lösung WEIL sie absurd ist

'Paul believes in the solution BECAUSE it is absurd'
}

As the explanans is restrictive (replacement by DENN sie ist absurd is impossible), we need to assume that if any part of an old/presupposed proposition is asserted, then this entire proposition is treated as having assertional illocutive force, that is, as a single-assertion construction. We cannot pursue the information-theoretic and prosodic repercussions of this issue any further. 
Table 2

Three types of explanatory sentences.

\begin{tabular}{|c|c|c|c|}
\hline & & \multicolumn{2}{|l|}{ Explanans } \\
\hline & & Asserted-foregrounded & Presupposed-backgrounded \\
\hline \multirow[t]{2}{*}{ Explanandum } & Asserted-foregrounded & $\begin{array}{l}\text { Appositive } \\
\text { double-assertion } \\
\text { construction }\end{array}$ & $\begin{array}{l}\text { Appositive } \\
\text { single-assertion construction }\end{array}$ \\
\hline & Presupposed-backgrounded & $\begin{array}{l}\text { Restrictive } \\
\text { single-assertion } \\
\text { construction }\end{array}$ & N.A. \\
\hline
\end{tabular}

without a delay around the connector. These conditions may give rise to a scenario where the speaker, about to launch the trailing explanans clause, already selects or utters a suitable conjunction but finds him/herself unable to continue fluently, thus forced to decelerate the speech tempo, to insert a filled (ehh, I mean) or unfilled speech pause, or to make a self-repair. Such scenarios may arise as a consequence of delayed onset of the conceptualizing process that should engender the propositional content of the explanans, and/or to a problem arising while the meaning content is encoded grammatically (e.g., a lexicalization, linearization, or morpho-syntactic problem). Delayed conceptualization may be due to signals from an interlocutor desiring an explanation of the proposition expressed in the just finished main clause (which ipso facto acquires the status of "explanandum"), or from the speaker him/herself who realizes the interlocutor needs a (more) convincing argument in support of the explanandum proposition (cf. Mercier and Sperber, 2011; Mercier, 2016). Confronted with such an impasse, the speaker may decide to close/discontinue/abandon the current (incomplete) sentence immediately, and to launch an entirely new, syntactically independent sentence as vehicle for the explanans proposition. Given verb-second as the canonical word order of main clauses in Dutch as well as German, this closure scenario leads to a V2 explanans, irrespective of whether the speaker selected want or omdat to announce the explanans clause. Notice that the resulting explanans clause has noncanonical word order only with omdat, not with want. Kempen and Harbusch (2016) argue that sentence planning problems are responsible for a sizable portion of weil-V2 clauses.

However, the option of applying closure and abandonment to a misplanned explanandum-cum-explanante sentence is available only to a subset of these sentences. In case of restrictive explanantia, the treatment would create a semantic anomaly. For instance, consider a driver who was fined for a traffic offense but intends to deny that the ticket was due to speeding. This speaker might use sentence (3), with a restrictive verb-final explanans clause within the scope of niet 'not'. Should the speaker continue with a V2 explanans (omdat ik heb te hard gereden 'for I was speeding'), which can only be interpret appositively, then s/he in fact denies being ticketed: The negation element cannot have scope over the appositive clause. (The same effect obtains when, in the English gloss, 'because' is replaced by 'for'.)

(3) $I k$ ben niet bekeurd omdat ik te hard gereden heb

I have-been not ticketed because I too fast driven have

'I haven't been ticketed because I was speeding'

Furthermore, since after closure the explanans proposition is couched in the form of an independent sentence with assertive illocutionary effect, V2 cannot apply to presupposed explanans propositions.

We conclude that V2 is ruled out in explanans clauses conveying a restrictive or a presupposed proposition. Table 3 summarizes the shapes of canonical and noncanonical types of explanans clauses discussed in this paper.

Table 3

Relations between explanans type, connector and word order in canonical and noncanonical explanans clauses. For characterizations of the explanans types, we refer to Table 2. Connectors doordat and aangezien are discussed in Section 4 (particularly footnotes 10 and 11).

\begin{tabular}{ll}
\hline Explanans type & Dutch \\
\hline Restrictive & omdat/doordat-VF \\
single-assertion & want-V2 \\
Appositive- & omdat-V2 \\
double-assertion & omdat-VF \\
& daar/aangezien-VF \\
Appositive- & omdat-VF \\
single-assertion & weil-VF \\
\hline
\end{tabular}


Table 4

Distribution of clause types in Dutch and German. Reproduced from Table 1 without absolute numbers. The percentages for denn-V2, weil-V2 and da-VF (all appositive) add up to 60.9. In Dutch, the appositive cases add up to $80.9 \%(=79.7 \%+1.2 \%)$. As argued in the text and indicated in Fig. 2 , we assume that $20 \%$ $(=80.9 \%-60.9 \%)$ of the weil-VFs must be appositive, leaving $19.1 \%(=39.1 \%-20.0 \%)$ restrictive weil-VFs.

\begin{tabular}{|c|c|c|c|}
\hline \multicolumn{2}{|l|}{ Dutch } & \multicolumn{2}{|l|}{ German } \\
\hline Clause Type & $\%$ & Clause Type & $\%$ \\
\hline want-V2 & 79.7 & denn-V2 & 16.2 \\
\hline omdat-V2 & 1.2 & weil-V2 & 34.1 \\
\hline omdat-VF & 18.3 & weil-VF & 39.1 \\
\hline doordat-VF & 0.8 & $d a-\mathrm{VF}$ & 10.6 \\
\hline Total & 100 & Total & 100 \\
\hline
\end{tabular}

\subsection{Comparing the Dutch and German data sets}

Why is omdat-V2 so much rarer than weil-V2? We propose to answer the focal question of this paper in two steps. In the present section, we analyze the cross-linguistic similarities and differences from the perspective offered by Table 4 and Fig. 2. In Section 4, we then present a simple neurocognitive model accounting for these data.

Before turning to our answer, we point out that Table 4 rules out two hypotheses that initially may look plausible. The first one assumes the target languages have similar proportions of subordinate VF and V2 explanans clauses. In the German corpus, the ratio of noncanonical to canonical weil clauses is 34.1-39.1: a ratio approaching 1:1. As the analogous ratio in the Dutch corpus of 1.2-18.3-a ratio close to 1:15-does not come anywhere near, the hypothesis is clearly rejected. The second hypothesis capitalizes on the very low number of omdat-V2s (only $1.2 \%$ ), which suggests the noncanonical linear orders do not stem from a systematic effect but merely from sloppiness on the part of the speakers. However, given that sloppiness is expected to affect VF and V2 clauses to similar degrees, this hypothesis predicts that these speakers also produce want-VF clauses-quod non. For a more promising avenue into a satisfactory answer, we therefore pay heed to the second salient contrast manifest in Table 4: the five times higher incidence of want (79.7\%) compared to denn (16.2\%).

It seems reasonable to work from the assumption that speakers of Dutch do not differ from speakers of German as regards the proportions of restrictive and appositive conceptual contents (propositions) expressed in the explanans clauses. From the Dutch data, we infer that $80.9 \%$ of the explanans clauses are appositive: the sum of all V2 clauses, as indicated by the big bracket flanking the Dutch bar in Fig. 2. The small bracket spans the remaining 19.1\%: the VF explanantia, all of which we assume are restrictive (hence foregrounded). The brackets flanking the German bar reflect the hypothesis of similar proportions of restrictive and appositive explanantia in the two target languages: The appositives include all V2s plus the $d a$-VFs, yielding 60.9\%. However, this underestimates the percentage of appositive explanantia in the German corpus by $20.0 \%$ (= 80.9\%-60.9\%; see the horizontal white line in the right column of Fig. 2). Apparently, the much lower incidence of omdat-V2 relative to weil-V2 is a consequence of take-over by want of the majority of appositive explanantia-even to such an extent that no appositive VFs are left in the Dutch data. ${ }^{7}$ In German, these tend to be realized by weil or da clauses (totaling $20.0 \%+10.6 \%=30.6 \%)$.

The take-over by want of appositive clauses cannot be the entire story, though, for two reasons. First, if want would appropriate the appositive clauses completely, this would rule out any omdat-V2s (but $1.2 \%$ is left). Second, if the low $16.2 \%$ of denn-V2s is entirely due to lexical frequency, then one would still expect a higher portion of appositive weil/da clauses: $80.9-16.2=64.7 \%$. However, the observed proportion is considerably lower-we obtained only $30.6 \%$, as mentioned above. This means a second factor must have been at work capable of turning the linear order in some portion of weil/omdat explanantia from object-verb to verb-object, thereby creating the weil-omdat-V2 phenomenon.

In the next section, we propose a production model in which word order selection is controlled not only by accessibility of the connectors in the mental lexicon, but additionally by attraction exerted by assertive illocutionary force on V2.

\footnotetext{
${ }^{6}$ The origin of this difference is historical. In Middle Dutch, the dominant causative conjunction was want, which selected V2 as well as VF (van Megen, 2002). Want was also the dominant causative conjunction in Old High German, Middle High German and early New High German, also licensing V2 and VF (Freywald, 2010:68-70). Selting (1999) describes the gradual replacement of want by weil and denn. In Dutch, another development has taken place: Want has survived until the present day, but now licensing only V2; its earlier function as subordinating conjunction has been taken over completely by omdat and doordat (and by a few low-frequent conjunctions such as daar and aangezien).

7 Strictly speaking, we cannot rule out that some portion of the omdat-VF clauses (19.1\%) is also appositive. In particular, this portion may include the equivalent of German $d a-V F$ clauses, which are appositive and backgrounded/presupposed, as indicated in Table 3. Verification would require inspection of the original spoken recordings and judging restrictive vs. appositive status on the basis of that material.
} 


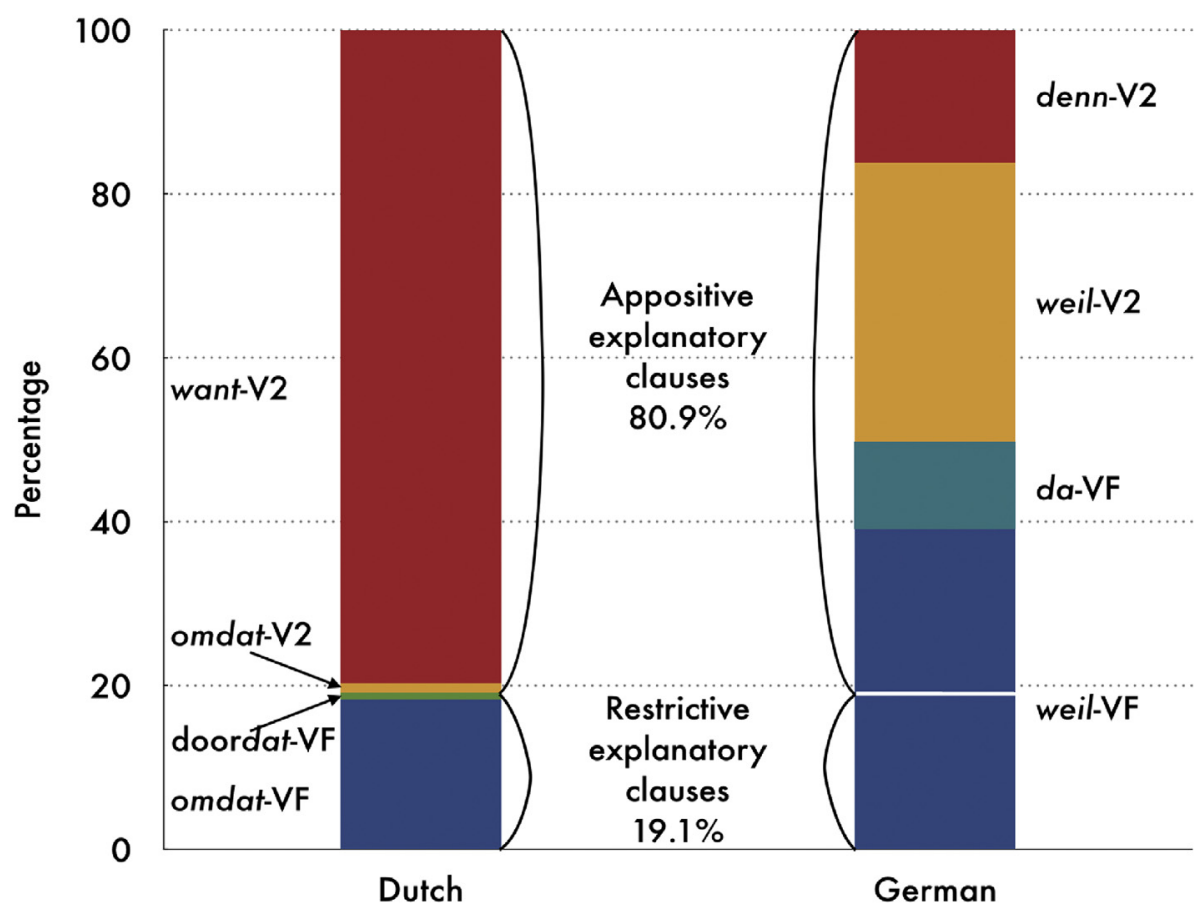

Fig. 2. Data of Table 1 with percentages of restrictive and appositive clauses added. The horizontal white line in the German bar shows that about half of the weilVFs must be appositive, on the assumption that speakers of the two languages conceptualize similar proportions of restrictive and appositive explanatory propositions.

\section{A simple neurocognitive production model}

The explanans production process we propose comprises three subprocesses familiar from the literature: conceptualization, lexicalization, and linearization (cf. Kempen, 1977; Levelt, 1989; Kempen and Harbusch, 2003). During the conceptualization step, the speaker composes an explanans proposition embedded in one of the three types distinguished in Table 2. The model's duty is to make two binary decisions: to select a connector type (coordinating or subordinating ${ }^{8}$ ), and a constituent order (V2 or VF). The lexicalization step selects a subordinating connector for single-assertion explanans propositions-restrictive or appositive-, but a coordinating or subordinating connector for double-assertion explanantia. The linearization step builds a clause with VF or V2 constituent order. The model consists of two processing modules couched in the form of simple neural nets (Fig. 3).

Input to the model are decisions taken by the Conceptualizer: a restrictive or an appositive explanans proposition, which the speaker assumes is either new or known to the audience. The two options between which a module/layer has to decide are represented by neural units ("nodes"). The initial level of activation of the nodes is zero, their maximum level is one. Each node has an above-zero activation threshold, which covaries with its frequency of use: A lower threshold means that the node needs less input activation to get triggered into action (i.e., to start transmitting activation to the next module, via a connection symbolized by an ascending arrow). The amount of activation transmitted by a node covaries with the node's current activation level. Within a module, the two nodes compete with one another by mutual transmission of inhibition ("negative" activation, reducing the activation level of the inhibited node). The higher the activation level of a node, the more inhibition it can send to its competitor. The node with the higher initial activation level usually emerges as winner of the competition, having defeated its opponent by reducing the latter's activation to a subthreshold level. The winner then determines the ensuing course of events, as it is the only node capable of transmitting activation to the next processing component ("winner takes all" within each module/layer separately). However, random amounts of activation or inhibition ("noise") may be added to the current activation level of a node, thus creating the opportunity for an initially weaker competitor to sometimes emerge as winner, or to escape from a stalemate.

The production of single-assertion constructions is handled by excitation flowing in the left-hand column. All three nodes in this column win the competition for the simple reason that none of the opponents in the other column receive activation (or at most small amounts of noise activation that do not pose a threat). The production of double-assertion constructions

\footnotetext{
${ }^{8}$ The model does not deal with the selection of individual connectors.
} 


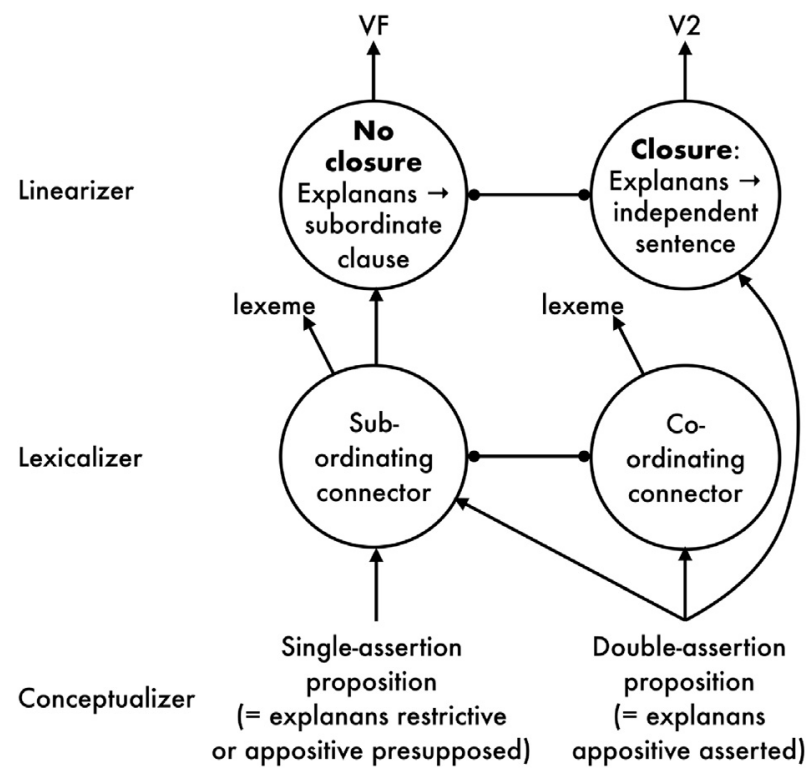

Fig. 3. Neural circuit consisting of two processing modules controlling the speaker's lexical (lemma), and word order choices in response to the type of proposition delivered by the Conceptualizer. Excitation spreads unidirectionally from lower to higher components ( $\rightarrow$ ). Within the lexicalization and linearization module, there is bidirectional spread of inhibition $(\bullet-\bullet)$. The slanted arrows ascending from the Lexicalizer nodes represent activation of the connector's phonological wordform ("lexeme").

starts in the right-hand column but spreads to the left-hand column as well, triggering competition within the Lexicalizer and the Linearizer. This competition mirrors the fact that, in both target languages, appositive explanans clauses can open not only with a coordinating but also with a subordinating connector. We assume that foregrounded appositive explanans propositions activate the Closure node in the Linearizer directly, without the intervention of a connector lemma governing this word order, thus "preselecting" V2 (even enabling foregrounded appositive explanans clauses to be realized as independent sentences without any causative conjunction). As a consequence, the two connector types entertain differing relations with the ensuing word order: VF order is governed by the connector (as indicated by the link ascending from the subordinating connector node); V2 order is activated directly by type of explanans proposition (via the curved arrow ascending from explanans type).

Competition within the Lexicalizer module accounts for the fact that speakers of Dutch strongly prefer want when planning a foregrounded (new, asserted) appositive explanans, whereas speakers of German prefer weil (79.7\% and 83.8\%, respectively). The outcomes of the lexical competitions, including their relative frequencies, are modulated by the Linearization module. The word order competition running there, which is directly influenced by explanans type via the curved arrow, may revert the outcome of the lexical competition by telling the system to close the current sentence and to grammatically encode the explanans proposition as the main clause of an independent sentence with default V2. This requires the Closure node to be activated by a to-be-asserted appositive proposition. The effect may be characterized as attraction ${ }^{9}$ of V2 by appositive propositions with assertive illocutionary force. It is this second competition that accounts for the higher ratio of noncanonical vs. canonical weil clauses in German (almost 1:1) than in Dutch (about 1:15).

Using the Simbrain3.0 neural-network software package (Tosi and Yoshimi, 2016), we designed a simulation of the model described here. Without going into details, we report here that runs with the simulation program yielded proportions of VF and V2 clauses that closely fit the Dutch and German proportions observed in the corpora. Crucially, the language-specific versions of the program differed only with respect to (the model's representation of) the frequencies of omdat and want compared to weil and denn. No other adaptations to the target languages were required to obtain this close fit. ${ }^{10}$

As for the low-frequency subordinating connectors doordat and daar/da, the model is able to account for the (near) absence of V2 constructions in the clauses they introduce, provided the following additional assumptions are valid: (1) Doordat is always used as a causative (as opposed to argumentative) connector, functioning as a restrictive modifier (thus

\footnotetext{
9 This attraction is probabilistic, not deterministic/absolute. There is no guarantee for the Closure node to win the competition and to obtain V2 in $100 \%$ of cases. If this node is defeated, the emerging result will be a subordinate clause with canonical VF word order but with assertive illocutionary force (a possibility argued for by Reis, 2013).

${ }^{10}$ Details concerning the simulation runs and the extracted corpus data are available upon request from the second author.
} 
triggering solely the left column of the model and preempting competition from the Closure node. ${ }^{11}$ )(2) The daar and da conjunctions are licensed by presupposed and backgrounded appositive propositions, i.e. by propositions that the speaker assumes already belong to the common ground (thus also triggering only the left column of the model ${ }^{12}$ ).

Finally, the model brings an unexpected bonus. Having seen many causative VF and V2 clauses, we started wondering why speakers rarely, if ever at all, replace an already uttered weil/omdat by denn/want when experiencing an explanans planning problem. We did find a few connector repetitions (e.g. weil ... weil ...; or even wei ... weil ... and om ... omdat ...) but no replacements of weil by denn, or of omdat by want. Degand (2016:427) made the same observation. We suggest that inhibition between the connectors is responsible for this effect: In order for a connector to emerge as winner of the competition, it must suppress the competitors to a below-threshold level of activation, making them nearly irretrievable at short notice.

\section{Conclusion}

The main new result revealed by the corpus study reported in this paper is the much lower relative frequency of omdat-V2 compared to its German pendant weil-V2. Another, well-known difference is the much higher incidence of the coordinating explanatory conjunction want in spoken Dutch than that of its pendant denn in spoken German. We propose a simple neurocognitive model that accounts for the former observation by taking the latter as point of departure. Input to the model is the format of the proposition delivered by the Conceptualizer: a double- or a single-assertion proposition. The Lexicalization module chooses a subordinating or coordinating connector. The Linearization module selects VF vs. V2 linear order. The selection processes within the modules are based on inhibitory competition between two neural nodes, each representing one on the choice alternatives.

The competition in the Lexicalizer yields cross-linguistically differing results due to the fact that, in Dutch, the most frequent explanatory connector takes V2 canonically whereas the most - and almost equally-frequent German explanatory connector takes VF canonically. The competition in the Linearizer, which does not differ between languages, causes doubleassertion propositions to attract V2 order (by inhibiting VF), and single-assertion propositions (including restrictive ones) to attract VF (by inhibiting V2). In Dutch, the canonical order licensed by the most popular connector matches the order attracted by double-assertion propositions (V2); in German, however, the most popular connector licenses a canonical order (VF) that is opposite to the order licensed by double-assertion propositions (V2). As, in both languages, the large majority of explanandum-cum-explanante sentences embodies a double-assertion construction, the result is fiercer competition within the German than in the Dutch instantiation of the model, engendering higher proportion of noncanonical orders after weil than after omdat.

A crucial property of our production-oriented model is the combination of an assumption about the conceptualization process (the speaker composing a single- vs. a double-assertion proposition) with one on the linearization process (the

\footnotetext{
${ }^{11}$ However, there may be syntactic pressures triggering Closure, not only in speech but even in (presumably) unedited written text. One such pressure is due to complexities of syntactic planning, in particular when a doordat clause (or an omdat clause, for that matter) includes a center-embedded subordinate clause. In Google, we found several doordat-V2 cases, searching with doordat wanneer 'because when' and doordat als 'because if. Here, a conditional clause is center-embedded within the causative clause-a structure known to tax working memory heavily. The finite verbs in noncanonical V2 position are underlined. Notice the strictly causative (objective, scientific, technical; as opposed to argumentative (in the sense of Mercier, 2016) content of the examples). (The causative/argumentative distinction concurs in part with the one between objective/subjective and between propositional/epistemic explanations; see Section 6.)

(i) Je kan dit intuïtief inzien doordat als je deelt door iets heel

You can this intuitively understand because when you divide by something very

klein, dan wordt de breuk zeer groot

small, then becomes the fraction very big

'You can understand this intuitively because when you divide by something very small, the fraction becomes very big'

(ii) Dit komt doordat als hout geïmpregneerd wordt, wordt er een op water This comes because when wood impregnated is is there a on water gebaseerd laagje overheen gespoten based layer over sprayed 'This is because when wood is impregnated, a water-based layer is sprayed over it'

(iii) Dat komt doordat als er veel licht schijnt, is er meer fotosynthese that comes because when there much light shines is there more photosynthesis 'That is because when much light shines, there is more photosynthesis'

(iv) Het verschil kan ik verklaren doordat wanneer je suiker verhit ontstaat vaste The diference can I explain because when you sugar heat $\overline{\text { results }}$ solid koolstof, maar ook gele rook carbon but also yellow smoke 'I can explain the difference because when one heats sugar, solid carbon results, but also yellow smoke'

12 Probably, this also accounts for the absence of aangezien-V2 cases. Interestingly, this conjunction originates from a passive participle translatable as seen, with the ensuing explanans proposition functioning as theme (subject). This construction thus expresses more or less explicitly that the explanans proposition is already known, i.e. presupposed.
} 
speaker deciding whether or not to close/abandon the current sentence when transiting from explanandum into explanans clause and to couch the explanans proposition in the form of an autonomous sentence/clause). As these decisions are taken by different modules, they are not necessarily compatible with one another. Moreover, they may conflict with decisions within the Lexicalization module whose task it is to select an appropriate conjunction while partly at the mercy of the vagaries of activation levels of competing candidate items. As a consequence, speakers sometimes fail to steer a straight course from double-assertion proposition via coordinating conjunction and closure of the current sentence to an independent V2 explanans, or from a single-assertion proposition via subordinating conjunction and avoidance of closure to a dependent/ integrated VF explanans.

The scenarios enabled by this system provides plausible accounts for the five properties of omdat/weil-V2 listed in the Introduction.

1. Deviations from the above "straight courses" are more likely under conditions of higher cognitive processing load, that is, during spontaneous speaking rather than during careful, edited writing.

2. Omdat/weil-V2 clauses occur only in trailing position because they function as second assertion in a double-assertion explanatory construction.

3. The same holds for want/denn-V2 clauses.

4. Omdat/weil-V2 clauses do not occur in elliptical answers to waarom/warum 'why' questions because the non-elliptical version of the answer is a single-assertion explanandum-cum-explanante sentence with the explanandum and explanans propositions representing old/presupposed and new/asserted information, respectively (in other words, the explanans is a restrictive modifier). ${ }^{13}$

5. Want/denn-VF cases do not occur because the VF node in the Linearizer, which in such cases is not triggered from Conceptualizer or Lexicalizer, only receives limited amounts of activation due to noise. Its competitor V2 does receive activation (from the Conceptualizer), and is certain to suppress the VF node, unless the level of noise-based activation received by the VF node would be unduly high.

\section{Discussion}

In this final section, we comment on how the account of omdat-V2 developed in the present paper and in its predecessor (Kempen and Harbusch, 2016) relates to accounts in the linguistic literature. We need not go into detail, given our discussion of these topics in the predecessor article. Here, we focus on how our distinction between single- and double-assertion explanatory constructions relates to similar distinctions in the literature, in particular to those between objective and subjective causative clauses (Pander Maat and Sanders, 2001; Spooren et al., 2010; Sanders and Spooren, 2015), and between epistemic and propositional explanations (see Reis, 2013 Kempen and Harbusch, 2016; and the literature cited there). The notion of subjectivity is defined by Spooren et al. (2010:241) as follows: "Subjectivity is understood as the degree to which the conceptualizer - the person responsible for the causal relation-is present in the utterance." They illustrate this notion in terms of sentences in (4) (their first three examples):

(4) (a) Jan is niet thuis omdat hij weg moest 'Jan is not at home because he had to leave'

(b) Ik weet zeker dat Jan niet thuis is, want zijn auto is weg 'I am sure that Jan is not at home, because his car is gone'

(c) De boom viel om omdat de bliksem insloeg 'The tree fell because it was struck by lightning'

Sentence (4b) is assumed to represent a higher level of subjectivity than (4a) because the "subject of conceptualization" is the speaker, whereas in (4a) it is another person. Both (4a) and (4b) are more subjective than (4c) because "both crucially involve an animate subject, a person, whose intentionality is conceptualized as the ultimate source of the causal event, be it an act of reasoning or some 'real-world' activity" (Pander Maat and Sanders, 2001:251). In fact, (4c) is called "objective", being "a truly conceptualizer-independent example [...] which describes a case of real-world physical causality" (Spooren et al, 2010:242).

\footnotetext{
13 However, our account leaves open the possibility that omdat/weil-V2 in responses to waarom/warum question are due to a problem with planning the conceptual content of the answer, which may trigger closure of the explanans clause and delivery of the finally conceptualized content in the form of an independent V2 main clause (such production scenarios are described by Kempen and Harbusch, 2016). Consider this imaginary (but not unrealistic) example that could occur during an oral exam:

Q: Waarom zijn veel planten groen?

Why are many plants green?

A: Omdat ... ze bevatten chlorofyl

Because ... they contain chlorophyl
} 
Example pair (4b) and (4c) also illustrates the epistemic vs. propositional distinction: (4c) is propositional because the omdat clause describes the cause of the explanandum event. On the other hand, the relation in (4b) is epistemic: the absence of Jan's car is the evidence used by the speaker to justify his/her judgement.

Spooren et al. (o.c.) report a study with a data set of 149 want sentences and 124 omdat sentences randomly selected from the same spoken language corpus we used (omdat-V2 cases were not included in their data set). They scored the level of subjectivity of the sentences, and determined whether the explanans clauses were epistemic or propositional. They found that want sentences tend to be more subjective and to include an epistemic explanans more often than omdat sentences.

We can explain this data pattern in terms of our distinction between single-assertion and double-assertion constructions if we make the following additional assumption (motivated in Kempen and Harbusch, 2016): In a double-assertion construction, the explanans proposition underlying the second assertion is conceptualized by the speaker after, and at least partly in response to, the explanandum proposition underlying the first assertion. (By this assumption we equate explanatory doubleassertion constructions with pairs of consecutive sentences where the second assertion explains the first. No prosodic repercussions in the form of pauses or intonation contours are expected if planning the second assertion proceeds smoothly, allowing it to take place during a time interval that overlaps, at least partly, with overt delivery of the first assertion.) The temporal interval allows the speaker to take note of effects the first assertion exerts on the audience-for instance, signs suggesting that the assertion is controversial and needs more convincing argumentation-, thus motivating the speaker to search the current knowledge base for additional arguments, and to conceptualize a second assertion that justifies (supports, strengthens) the first one (Diessel and Hetterle, 2011; Mercier, 2016; see also Section 3.1 above):

$$
\text { JustifiedBy(Propexp'um, Propexp'ns) }
$$

Another possible reaction by the speaker to having uttered the first assertion may be the conceptualization of a counterargument. If this invalidates (weakens, refutes) the first assertion:

$$
\text { InvalidatedBy(Prop } \text { assert } 1, \text { Prop }_{\text {assert2 })}
$$

and activates the concessive subordinating connector hoewel/ofschoon 'although' (German: obwohl) in the right-hand (double-assertion) column of the model, the consequence is delivery of the second assertion with noncanonical V2 word order. (See Freywald, 2016, for a recent linguistic analysis of obwohl and other German conjunctions that occur with V2 order in the clause they introduce.)

Whether this temporal version of our account of (non)canonical V2 in terms of double-assertion constructions, is valid and can do without specific assumptions about subjectivity or epistemicity of the connected propositions-assumptions over and above predicates underlying discourse markers such as mentioned above (JustifiedBy, CausedBy, or InvalidatedBy in case of concessive relations) - , is a topic for further investigation.

\section{Funding}

This research did not receive any specific grant from funding agencies in the public, commercial, or not-for-profit sectors.

\section{Conflicts of interest}

None.

\section{Acknowledgments}

We are indebted to the editors and to two anonymous reviewers for their constructive comments.

\section{References}

Abraham, W., 2016. Was bedeutet Subordination mit V2 im Deutschen und Niederländischen: omdat und want ebenso wie weil und denn? Leuvense Bijdragen 99-100, 122-132.

Antomo, M., 2012. Projective meaning and the licensing of embedded root phenomena. In: Proceedings of ConSOLE XIX, pp. 1-23.

Antomo, M., 2015. Abhängige Sätze in einem fragebasierten Diskursmodell. Dissertation. Georg-August-Universität, Göttingen.

Antomo, M., 2016. Marking (not-)at-issue content by using verb order variation in German. In: Reich, I., Speyer, A. (Eds.), Co- and Subordination in German and Other Languages. Buske, Hamburg (Linguistische Berichte, Sonderheft 21).

Antomo, M., Steinbach, M., 2010. Desintegration und Interpretation. Weil-V2-Sätze an der Schnittstelle zwischen Syntax, Semantik und Pragmatik. Zeitschrift für Sprachwissenschaft 29, 1-38. 
Auer, P., 1997. Formen und Funktionen der Vor-Vorfeldbesetzung im gesprochenen Deutsch. In: Schlobinski, P. (Ed.), Syntax des gesprochenen Deutsch. Westdeutscher Verlag, Opladen.

Charvanel, I., 2017. Non-at-issueness of since-clauses. Abstract for SALT27. University of Maryland. May 2017. http:/lingsite.org/salt27/wp-content/uploads/ 2017/02/CHARNAVEL-NonAtissuenessOfSinceClauses.pdf. (Accessed 30 December 2017).

Debaisieux, J.-M., 2016. Toward a global approach to discourse uses of conjunctions in spoken French. Lang. Sci. 58, 79-94.

Degand, L., 2016. Omdat Ik heb tot half één tentamen: over nevenschikkend omdat in context. Nederl. Taalkd. 21, 419-431.

Diessel, H., Hetterle, K., 2011. Causal clauses: a cross-linguistic investigation of their structure, meaning and use. In: Siemund, P. (Ed.), Linguistic Universals and Language Variation. de Gruyter, Berlin.

Freywald, U., 2010. Obwohl vielleicht war es ganz anders: Vorüberlegungen zum Alter der Verbzweitstellung nach subordinierenden Konjunktionen. In: Ziegler, A. (Ed.), Historische Textgrammatik und Historische Syntax des Deutschen: Traditionen, Innovationen, Perspektiven. De Gruyter, Berlin.

Freywald, U., 2016. Clause integration and verb position in German - drawing the boundary between subordinating clause linkers and their paratactic homonyms. In: Reich, I., Speyer, A. (Eds.), Co- and Subordination in German and Other Languages. Buske Verlag, Hamburg [= Linguistische Berichte, Sonderheft 21].

Haegeman, L., 2006. Argument fronting in English, Romance CLLD and the left periphery. In: Zanuttini, R., Campos, H., Herburger, E., Portner, P. (Eds.), Crosslinguistic Research in Syntax and Semantics: Negation, Tense and Clausal Architecture. Georgetown University Press, Washington DC.

Haegeman, L., 2012. Adverbial Clauses,

Main Clause Phenomena, and the Composition of the Left Periphery. Oxford University Press, Oxford UK.

Haeseryn, W., Romijn, K., Geerts, G., de Rooij, J., van denToorn, M., 1997. Algemene nederlandse spraakkunst, second ed. Nijhoff, Groningen.

Haug, D.T.T., Fabricius-Hansen, C., Behrens, B., Helland, H.P., 2012. Open adjuncts: degrees of event integration. In: Fabricius-Hansen, C., Haug, D.T.T. (Eds.), Big Events, Small Clauses: The Grammar of Elaboration. De Gruyter, Berlin.

Hoekstra, H., Moortgat, M., Schuurman, I., van der Wouden, T., 2001. Syntactic annotation for the spoken Dutch corpus project (CGN). Lang. Comput. 37, 7387.

Kempen, G., 1977. Conceptualizing and formulating in sentence production. In: Rosenberg, S. (Ed.), Sentence Production: Developments in Research and Theory. Erlbaum, Hillsdale N.J.

Kempen, G., Harbusch, K., 2003. Dutch and German verb constructions in performance grammar. In: Seuren, P., Kempen, G. (Eds.), Verb Constructions in German and Dutch. Benjamins, Amsterdam.

Kempen, G., Harbusch, K., 2016. Verb-second word order after German weil 'because’: psycholinguistic theory from corpus-linguistic data. Glossa J. Gen. Ling. 1 (1), 1-32, 3.

König, E., Lezius, W., 2003. The TIGER Language: A Description Language for syntax Graphs; Formal Definition. Technical Report, IMS. University of Stuttgart, Stuttgart.

Levelt, W.J.M., 1989. Speaking: From Intention to Articulation. MIT Press, Cambridge MA.

Mercier, H., 2016. The argumentative theory: predictions and empirical evidence. Trends Cognit. Sci. 20, 689-700.

Mercier, H., Sperber, D., 2011. Why do humans reason? Arguments for an argumentative theory. Behav. Brain Sci. 34, 57-111.

Pander Maat, H., Sanders, T., 2001. Subjectivity in causal connectives: an empirical study of language in use. Cognit. Ling. 12, $247-273$.

Persoon, I., Sanders, T., Quené, H., Verhagen, A., 2010. Een coördinerende omdat-constructie in gesproken Nederlands? Tekstlinguïstische en prosodische aspecten. Nederl. Taalkd. 15, 259-282.

Quirk, R., Greenbaum, S., Leech, G., Svartvik, J., 1985. A Comprehensive Grammar of the English Language. Longman, London.

Reis, M., 2013. “Weil-V2”-Sätze und (k)ein Ende? Anmerkungen zur Analyse von Antomo \& Steinbach (2010). Zeitschrift für Sprachwissenschaft 32, 221262.

Sanders, T.J.M., Spooren, W.P.M., 2015. Causality and subjectivity in discourse: the meaning and use of causal connectives in spontaneous conversation, chat interactions and written text. Linguistics 53, 53-92.

Schäfer, R., Sayatz, U., 2017. Punctuation and syntactic structure in obwohl and weil clauses in nonstandard written German. Writ. Lang. Lit. $19,212-245$.

Scheffler, T., 2005. Syntax and semantics of causal denn in German. In: Proceedings of the 15th Amsterdam Colloquium. Amsterdam.

Selting, M., 1999. Kontinuität und Wandel der Verbstellung von ahd. wanta bis gwd. weil. Zur historischen und vergleichenden Syntax der weil-Konstruktionen. Z. Ger. Linguist. 27, 167-204.

Spooren, W., Sanders, T., Huiskes, M., Degand, L., 2010. Subjectivity and causality: a corpus study of spoken language. In: Rice, S., Newman, J. (Eds.), Empirical and Experimental Methods in Cognitive/Functional Research. CSLI, Satanford CA.

Tosi, Z., Yoshimi, J., 2016. Simbrain 3.0: a flexible, visually-oriented neural network simulator. Neural Network. 83, 1-10.

van Eerten, L., 2007. Over het Corpus Gesproken Nederlands. Nederl. Taalkd. 12, 194-215.

van Megen, N., 2002. Dan en want: hun functie en betekenis in zeventiende-eeuws taalgebruik. Neerlandistiek.nl. article 02.02. http://dspace.library.uu.nl/ handle/1874/28506. (Accessed 14 January 2017). 